\title{
OSTEOPHYTES AND THE OSTEOARTHRITIC FEMORAL HEAD*
}

\author{
A. K. Jeffery, Dunedin, New Zealanid \\ From the Department of Orthopaedic Surgery, University of Otago Medical School, Dunedin
}

The study describes the topography, morphology and growth of osteophytes in forty femoral heads removed from patients presenting with advanced osteoarthritis of the hip. In addition to standard histological techniques, radiography of serial bone slices and in vivo bone labelling with tetracycline and ${ }^{32} \mathrm{P}$ were used. The pattern of major osteophyte formation appeared to be influenced by the direction, degree and rate of displacement of the femoral head in relation to the acetabulum; four principal patterns of growth were noted. Osteophytes form part of extensive osteogenic processes that involve bone structure in the osteoarthritic joint.

Osteoarthritis is characterised by a progression of pathological changes commencing in articular cartilage, and ultimately affecting bone and soft tissues of the joint. One of the most distinctive of these changes, particularly in advanced stages of the disease, is the formation of bony outgrowths or osteophytes. The hip joint in comparison with other osteoarthritic joints often shows marked osteophyte formation, and changes involving the femoral head are usually more advanced than those seen in the acetabulum (Collins 1949).

Although a prominent feature of the disease, osteophytes form only part of continuing remodelling processes that affect bone structure throughout the joint. The present paper describes a study of osteophyte growth in the osteoarthritic femoral head, the pattern of growth being examined in relation to other changes occurring within the joint.

\section{MATERIAL AND METHODS}

Forty femoral heads from men and women undergoing total hip replacement for advanced osteoarthritis were studied. Sections of excised capsule and synovial membrane were also taken for histological examination. All patients were examined before operation and the affected hip assessed clinically and radiographically. Patients presenting with osteoarthritis that could be attributed to a specific pre-existing hip disorder, either congenital or acquired, were excluded from the series.

Ten patients were given a tracer dose of radioactive ${ }^{32} \mathrm{P}$ and tetracycline to label areas of new bone formation within the femoral head and neck. Bone sections were examined for uptake of these labels, using autoradiographic and ultra-violet fluorescent techniques previously described (Jeffery 1973).

Each excised femoral head was examined macroscopically, photographed and cut with a hand-saw into serial slices approximately 5 millimetres thick. In most specimens the slices were cut in a coronal plane to facilitate the correlation of the subsequent slab radiographs and whole-head histological sections with the pre- operative radiographs. Some specimens were cut in a sagittal or oblique plane to provide a different perspective of bone structure and osteophyte formation.

All slices were radiographed on fine grain industrial radiographic film (Kodak Microtex) using standard equipment with an exposure of 5 seconds at $48 \mathrm{kV}, 50 \mathrm{~mA}$ and a tube-to-specimen distance of one metre.

Whole-head histological sections of 10 to $12 \mu$ were prepared after decalcification of bone slices from the anterior, mid-coronal and posterior planes of the femoral head. A standard histological technique of double embedding with 2 per cent celloidin and wax was used, and three or four sections were prepared from each bone slice. Osteophytes were studied in more detail by cutting them from the remaining bone slices and preparing serial histological sections of 7 to $8 \mu$.

Undecalcified bone sections were also prepared by the method of Ball (1957). These sections, 7 to $8 \mu$ thick, were prepared from segments of bone taken from osteophytes and from within the femoral head, and examined for distribution of mineral after staining with a modified von Kossa technique. A 1 per cent solution of silver nitrate was used to avoid obscuring cellular detail and the sections were counterstained with 1 per cent Nuclear Fast Red.

The sections of capsule and synovial membrane were examined by routine histological and staining methods including the von Kossa technique to identify bone mineral lying within the synovial membrane.

With these methods osteophyte growth and changes affecting bone structure of the femoral head and neck could be examined in detail and correlated with the preoperative clinical and radiographic findings.

\section{RESULTS}

\section{Osteophyte morphology}

Osteophytes arising from and involving the femoral head were classified according to their location and direction of growth (Figs. 1 to 3).

Marginal osteophytes-These grow either at the peripheral

* Based on a paper presented at the annual meeting of the New Zealand Orthopaedic Association, Waitangi, October 1, 1973.

A. K. Jeffery, F.R.C.S., F.R.A.C.S., Department of Orthopaedic Surgery, University of Otago, Dunedin, New Zealand. 
margin of the femoral head or centrally at the margin of the fovea capitis. Bone growth commences in areas where synovium and cartilage merge and continues by a form of enchondral ossification (Fig. 4). The osteophyte surface is covered by fibrous tissue undergoing differentiation and cartilaginous metaplasia. Microscopically the superficial layer consists of closely arranged mesenchymal cells, while more deeply lie actively proliferating and differentiating cells. The deepest and most mature cells are rounded, often showing degenerative changes and surrounded by mineralised matrix. Enchondral new bone downwards from the central foveal area. Growth occurs partly within the superficial layers of the original articular cartilage, the deeper layers of which are buried and may later be gradually replaced by new bone (Fig. 5). Like the marginal osteophyte the surface of the epiarticular osteophyte is composed of differentiating fibrous tissue and fibrocartilage, and growth outwards from the femoral head is by enchondral ossification.

The epiarticular growth extends to involve existing articular cartilage. Growth was not found covering the surface of intact articular cartilage, nor extending over

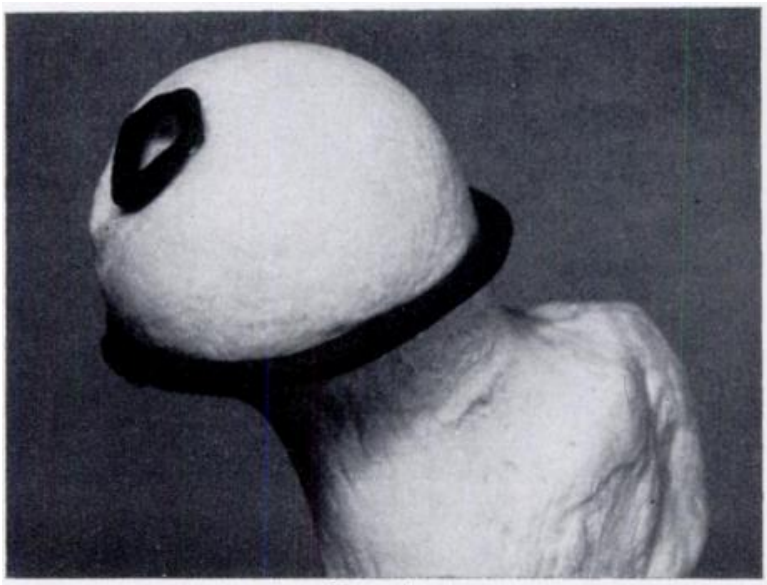

FIG. 1

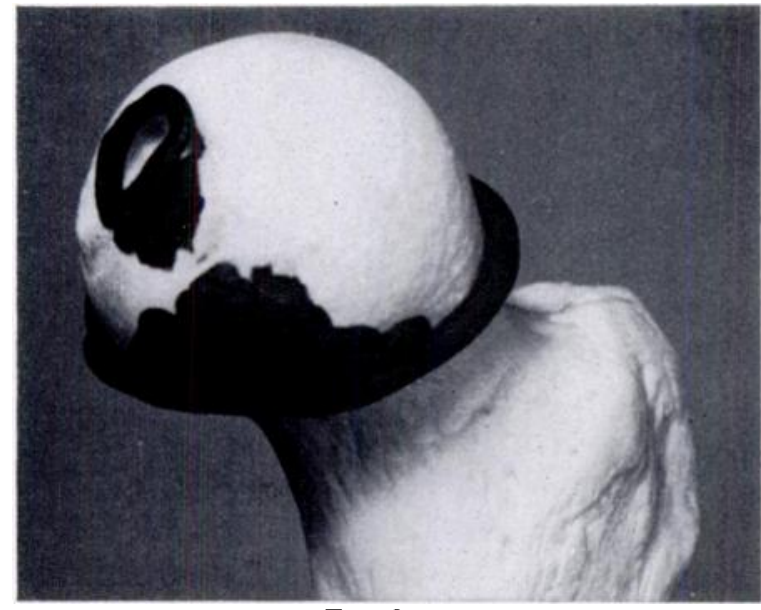

FIG. 2

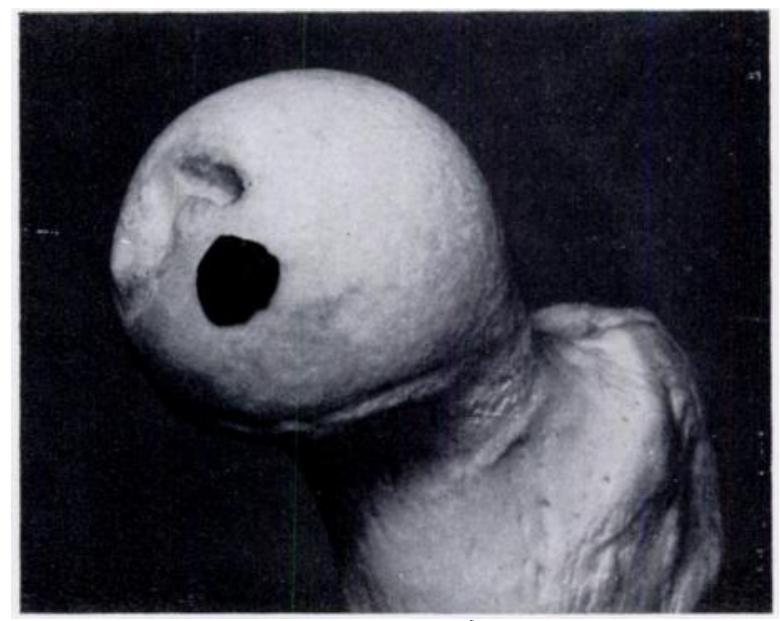

FIG. 3

Models showing the areas of principal osteophyte growth involving the osteoarthritic femoral head. Figure 1-Marginal osteophytes. Figure 2-Epiarticular osteophytes. Figure 3-Subarticular osteophyte.

and vascular channels extend into the zone of provisional mineralisation from the underlying bone marrow. Remodelling of trabeculae within the osteophyte is seen, and osteoid seams adjacent to newly formed trabeculae indicate the presence of active osteogenesis with appositional new bone formation (Jeffery 1973).

Epiarticular osteophytes-Growth of a marginal osteophyte may extend to involve the surface of the femoral head, forming an epiarticular osteophyte. The medial and postero-medial surface of the head is most commonly involved by this form of growth, which extends upwards from the peripheral marginal area or, less commonly, bony surfaces denuded of articular cartilage. The response of articular cartilage to invasion by the advancing osteophyte and its role in extension of the bony growth was examined (Fig. 6). Adjacent to the apex of the osteophyte the superficial layer of articular cartilage showed considerable cellular activity, with apparent proliferation and differentiation, with vascular invasion and enchondral new bone formation. Cells in the deeper zone of the articular cartilage showed a more limited response. Vascular invasion in this area was accompanied by cell degeneration, with new bone gradually replacing the existing cartilage matrix. 
Subarticular osteophytes-In osteoarthritis, microscopic areas of new bone formation are commonly seen extending across the chondro-osseous junction into the basal layers of degenerating articular cartilage. In the specimens examined, irregular plaques of bone formed in this way were noted, but these were commonly confined to the plaques lying beneath the periosteal and synovial reflection of the femoral neck, and new bone formation was in the deeper osteogenic layers of the periosteum.

Thickening of the calcar was also a constant finding. Successive layers of subperiosteal new bone formed on the surface of the calcar produced a characteristic

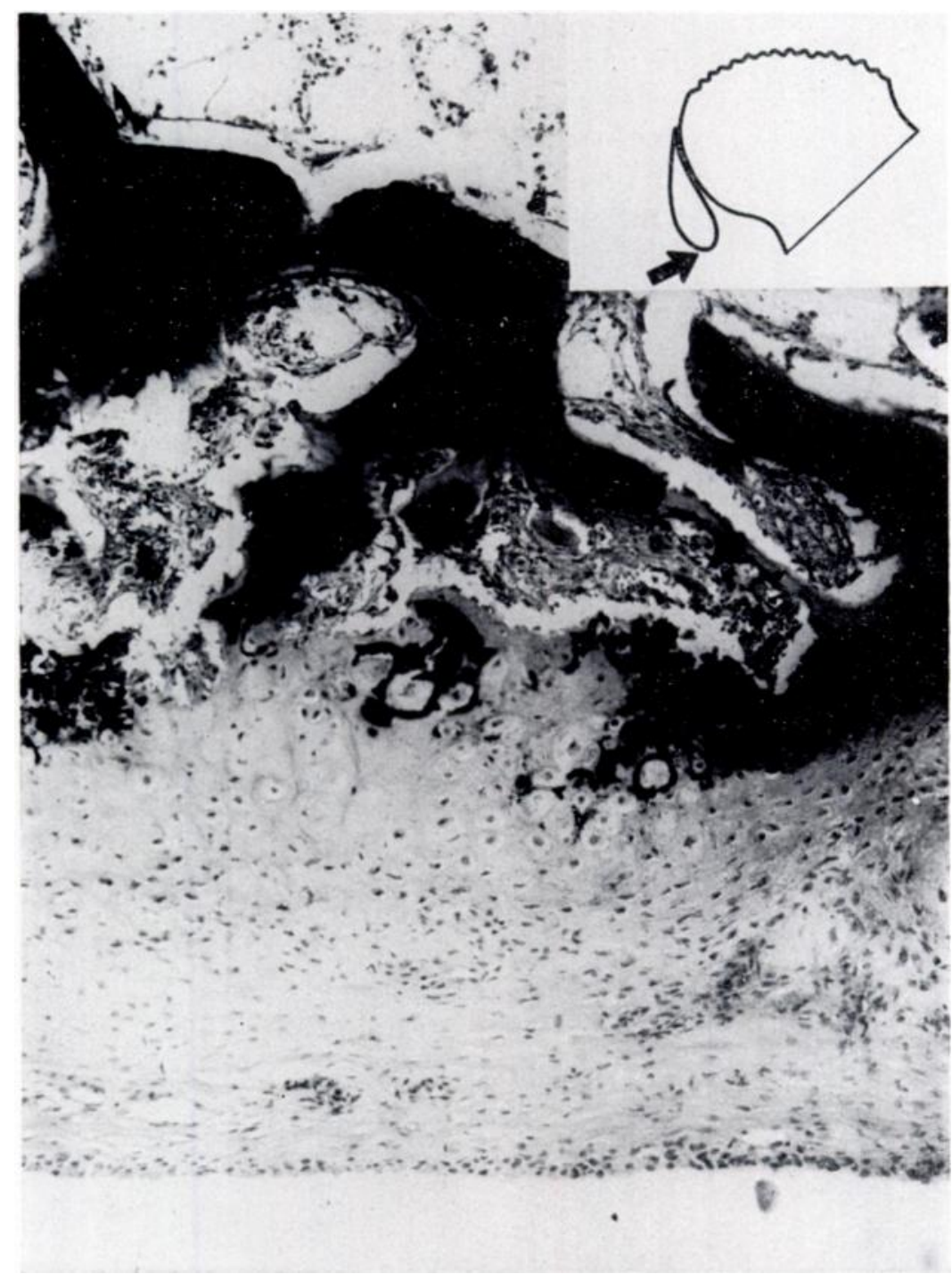

Fig. 4

Undecalcified section from the tip of a marginal osteophyte showing cellular differentiation and advancing enchondral new bone formation. Deep in the section, osteoid seams lie adjacent to newly formed trabeculae. (Von Kossa stain, $\times 135$.)

deeper zone of the articular cartilage and seldom produced a surface projection evident on macroscopic examination of the fresh specimen (Fig. 7). Prominent and apparently isolated osteophytes projecting from the articular cartilage were found on serial sectioning to be epiarticular growths arising from the central or peripheral marginal areas of the femoral head, and not subarticular growths arising from the subjacent bony surface.

Osteophytes and the femoral neck-Although the present study was concerned primarily with osteophytes related to the femoral head, bony outgrowths were frequently noted on the femoral neck. These formed nodules or laminated appearance on radiography of the coronal bone slabs, an appearance also commonly seen in the preoperative radiographs (Figs. 15 and 16). This thickening was described in congenital subluxation of the hip by Wiberg (1939) and in idiopathic osteoarthritis by LloydRoberts (1953), who suggested as a cause the elevation of the periosteum away from the neck of the femur by a traction force transmitted through the postero-inferior capsular reflection. Examination of the labelled specimens showed periosteal new bone extending beyond the areas of capsular reflection. Some specimens also showed endosteal new bone in the region of the calcar, suggesting 


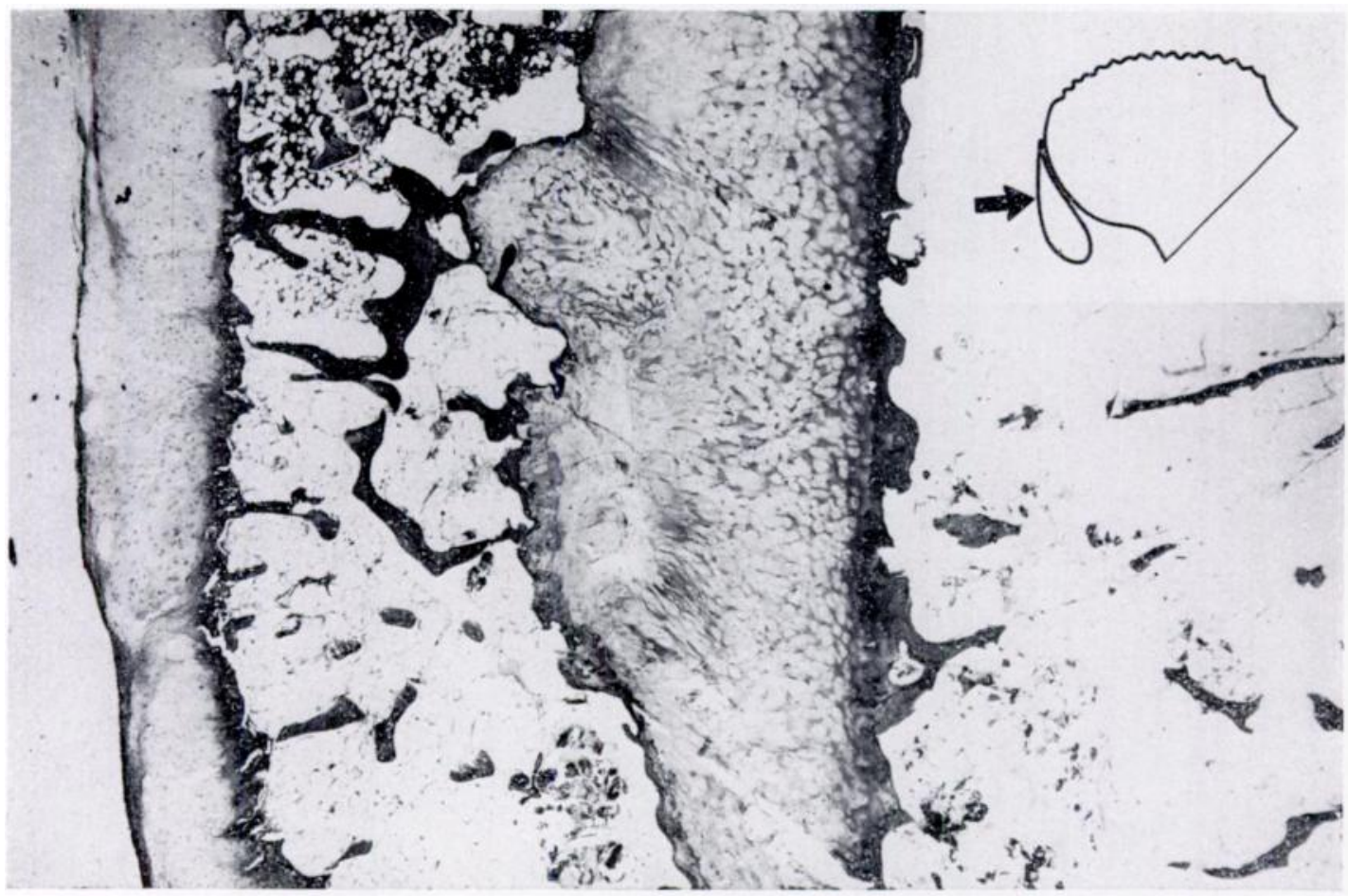

Fig. 5

Section through an epiarticular osteophyte involving the medial surface of the femoral head. The original articular cartilage seen at the right of the section is buried and partly replaced by new bore. (Haematoxylin and eosin, $\times 14$.)

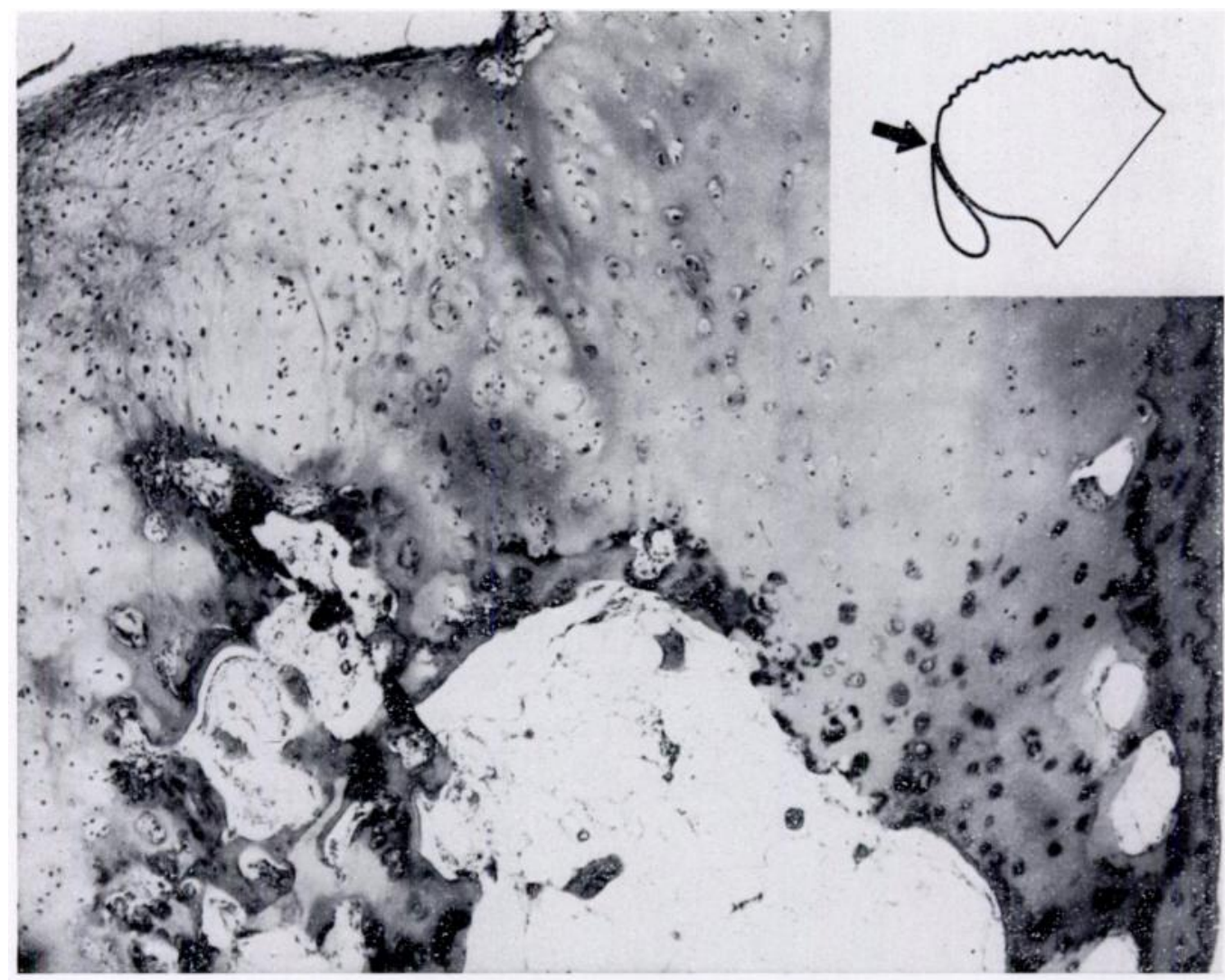

Fig. 6

Section from the apex of an epiarticular osteophyte advancing into articular cartilage. Cellular activity and enchondral new bone formation appear more prominent in the superficial layers of the cartilage. Vascular invasion and mineralisation of matrix in the deeper layers are accompanied by less cellular response. (Haematoxylin and eosin, $\times 58$.) 


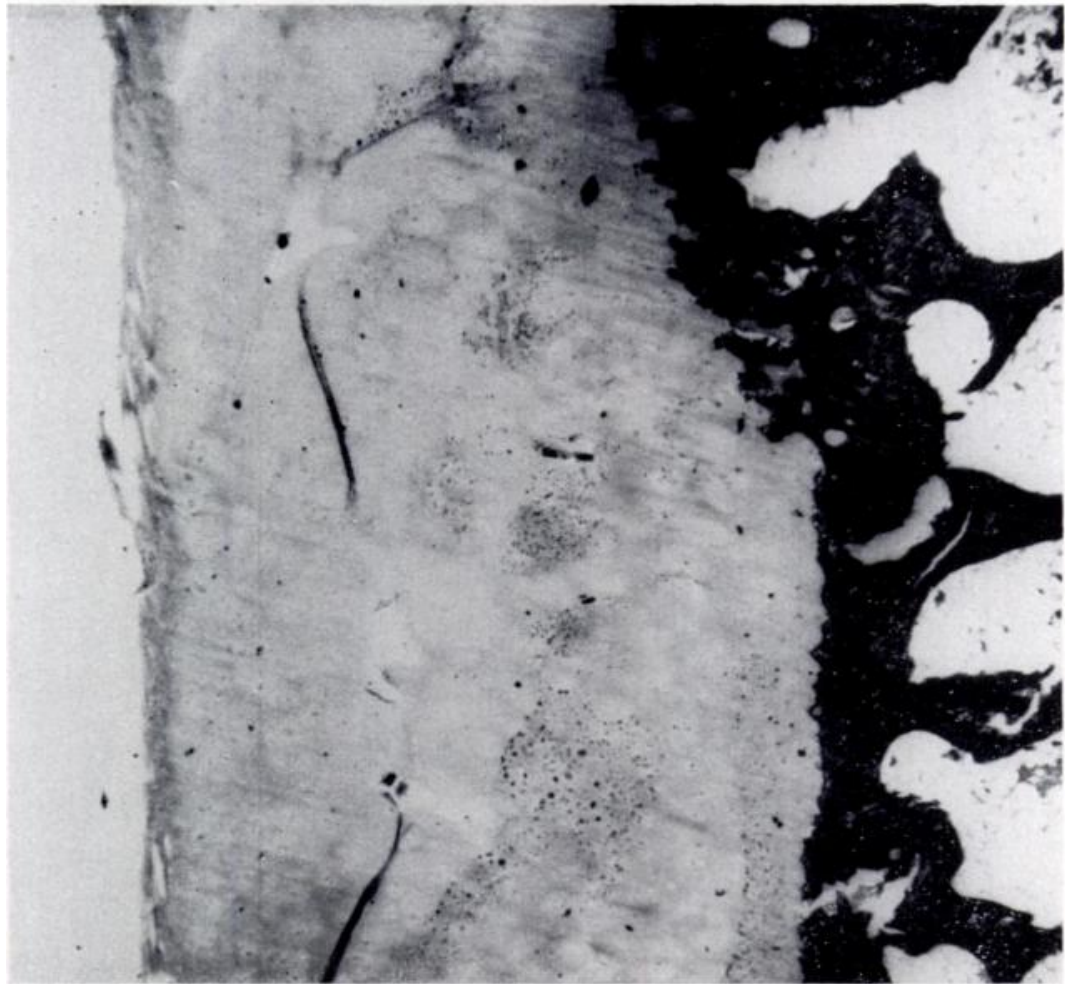

Fig. 7

Undecalcified section showing subarticular formation of new bone extending into the basal layers of degenerating articular cartilage. The new bone is seen at the top of the section and there is no accompanying surface projection. (Von Kossa stain, $\times 28$.)

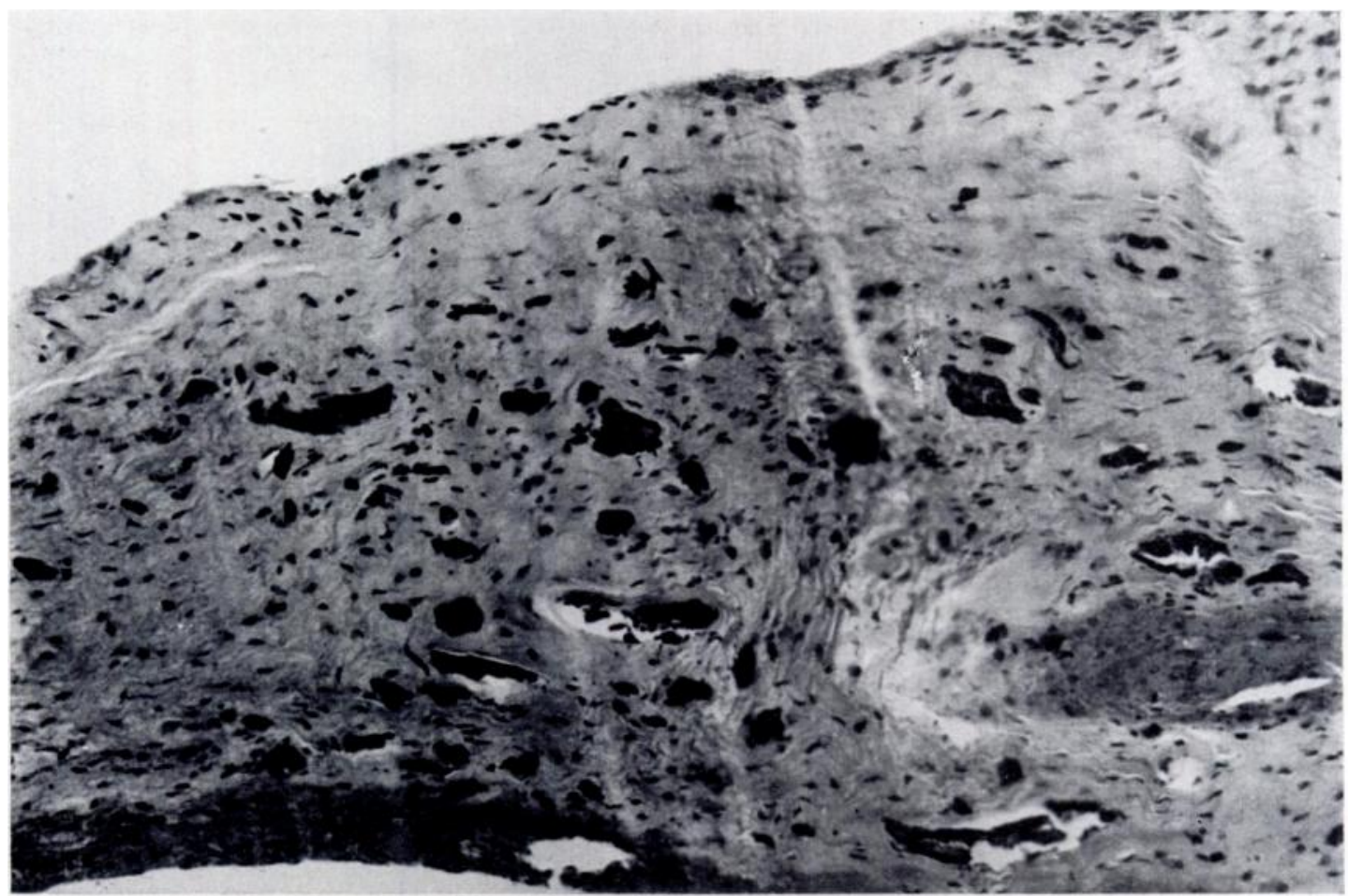

FIG. 8

Section of hypertrophied synovial membrane from the articular margin. Considerable bone detritus lies within the membrane. (Von Kossa stain, $\times 175$.) 
that the thickening is formed principally in response to abnormal stress, as originally proposed by Wiberg.

tissue (Fig. 8). Elsewhere in the specimens the synovium Capsule and synovial membrane-Specimens of excised was often thin or completely absent, being replaced by fibrous tissue.

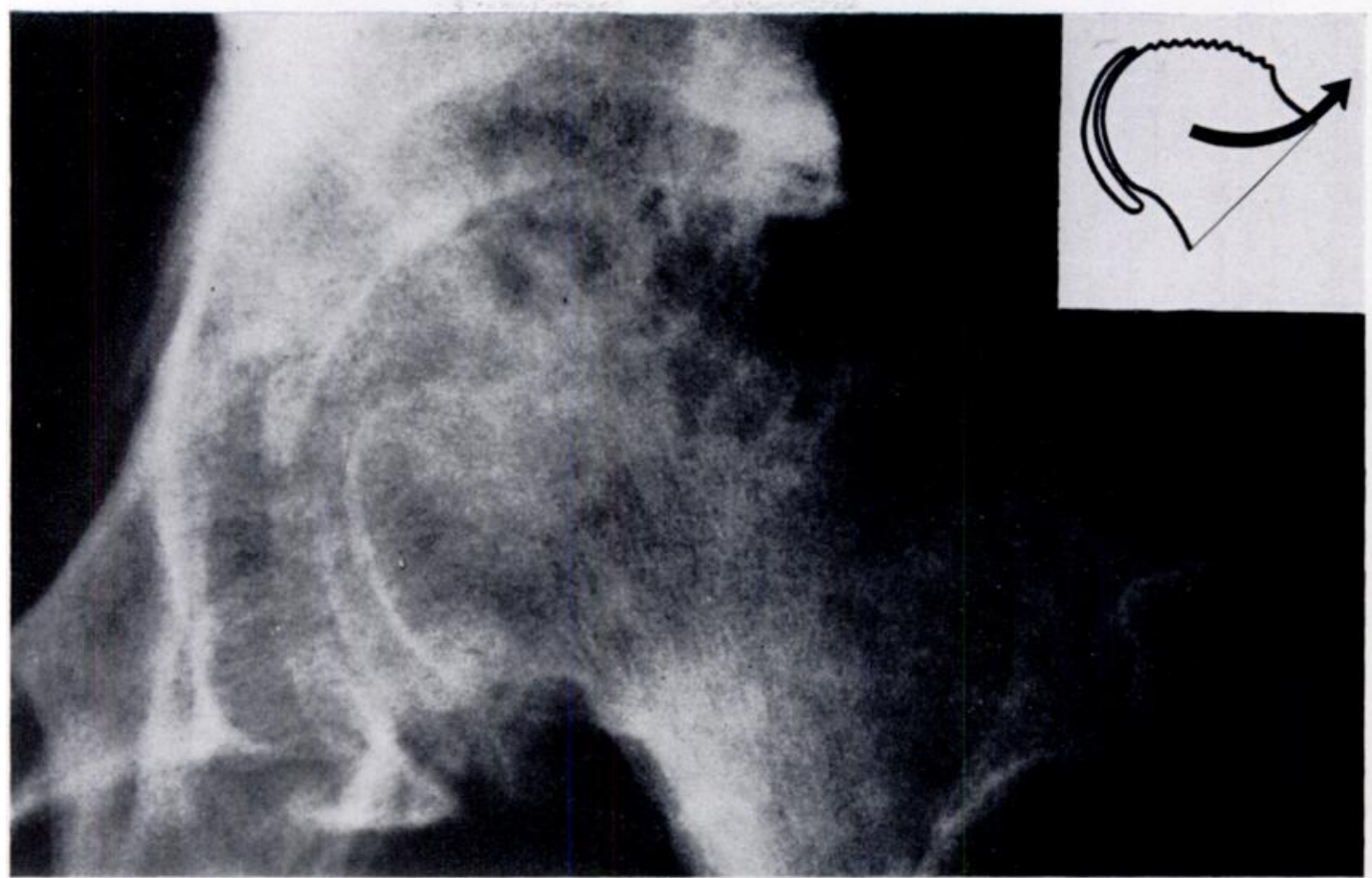

FIG. 9

Radiograph of an osteoarthritic hip showing Type I pattern of changes. Sphericity of the femoral head is maintained but lateral rotation and lateral displacement within the acetabulum are present. An epiarticular osteophyte extends over the medial surface of the head and the calcar is thickened.

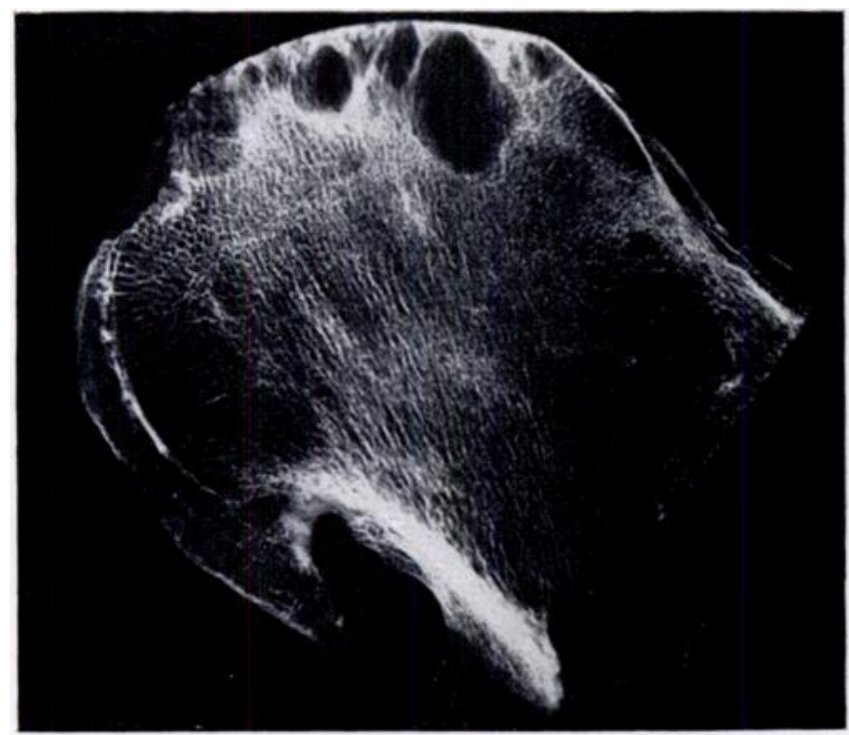

Fio. 10

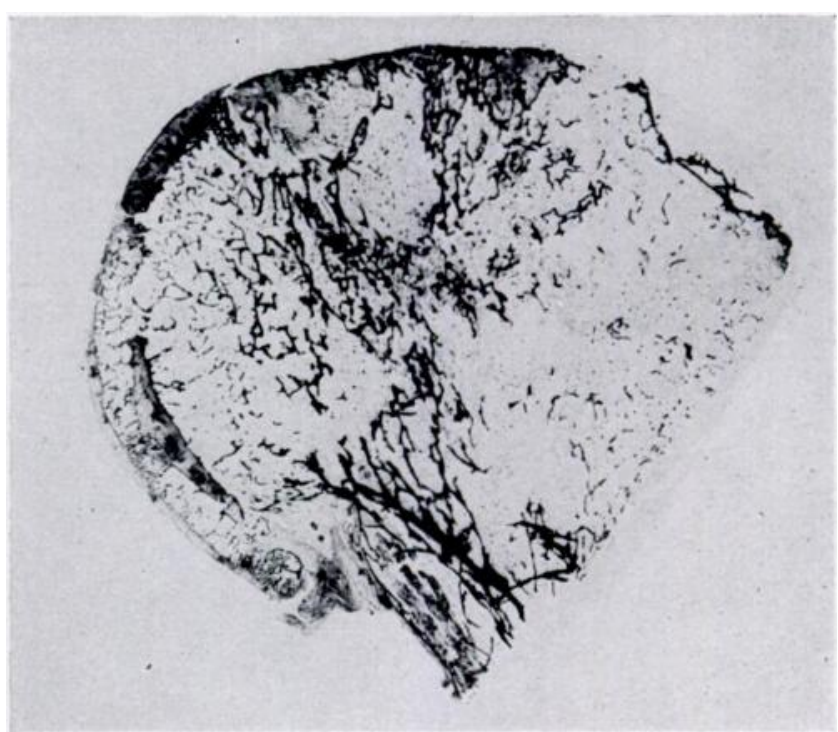

Fig. 11

Figure 10-Radiograph of a midcoronal bone slice from the femoral head shown in Figure 9. The medial epiarticular osteophyte has buried the original articular cartilage and the calcar is thickened by layers of subperiosteal new bone. Figure 11-Histological section taken from same femoral head. Loss of articular cartilage, eburnation of bone and cyst formation are most prominent in the superior and lateral segment of the section.

capsule typically showed extensive fibrosis, with thickening and loss of elasticity. Hypertrophy and villous formation of the synovial membrane was most prominent at the joint margins, both peripherally and centrally. Histological sections from these areas showed considerable amounts of joint detritus lying within the synovial

\section{Osteophyte growth patterns}

Although the osteophyte formation on each femoral head varied considerably, the shape and distribution of principal growth appeared related to other changes occurring in the joint. Four main patterns of osteophyte formation were commonly seen. 
Type I (Figs. 9 to 11)-This group was characterised by a broad flat epiarticular osteophyte involving the medial and postero-medial aspect of the femoral head. Sphericity of the head was reasonably maintained, although degener- were commonly noted on clinical and radiological examination of the joint.

Type II (Figs. 12 to 14) -In this group the medial epiarticular osteophyte projected outwards and downwards

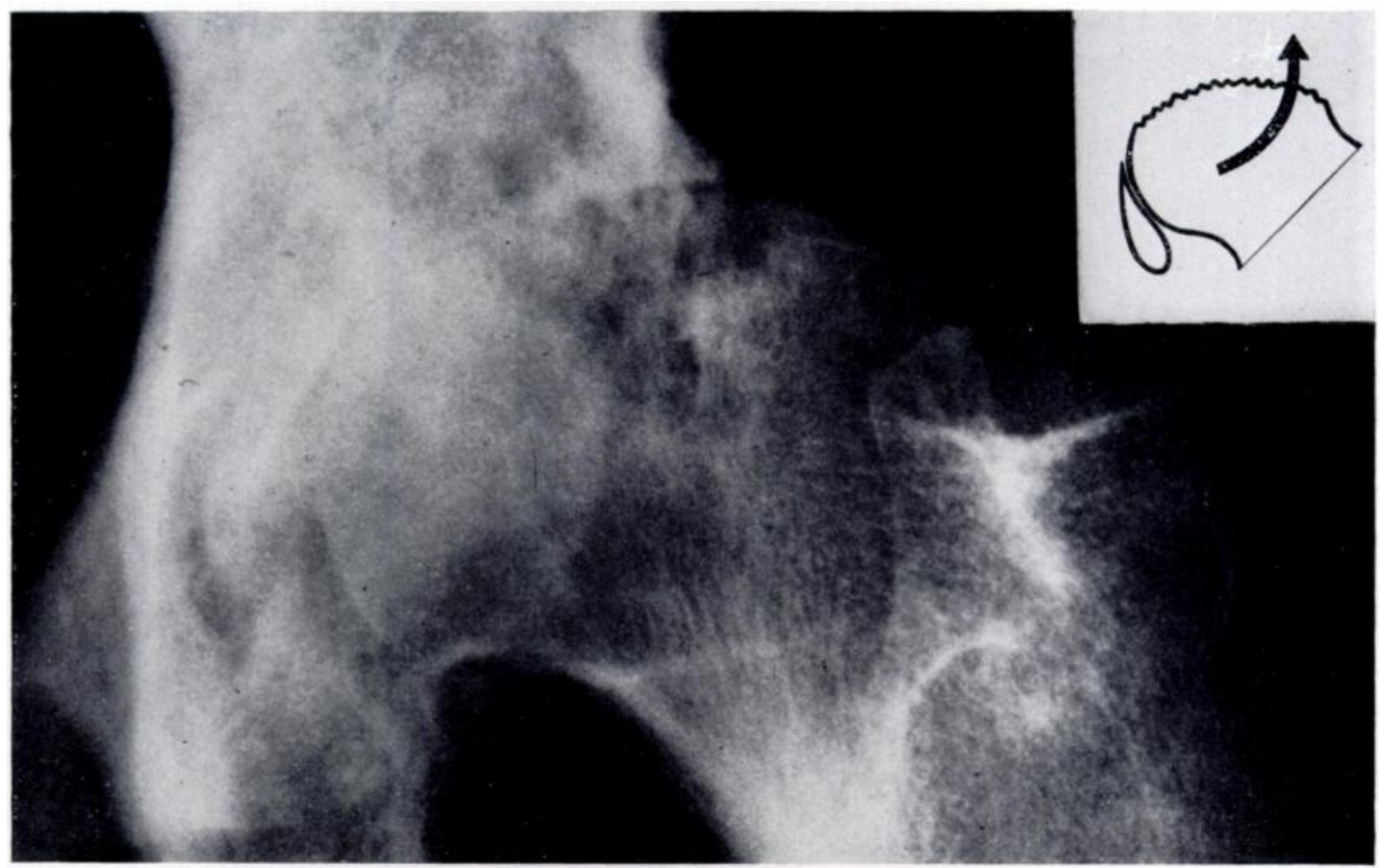

FIG. 12

Radiograph of an osteoarthritic hip showing Type II changes. The femoral head is considerably deformed and displaced upwards and laterally in relationship to the acetabulum. The calcar is thickened.

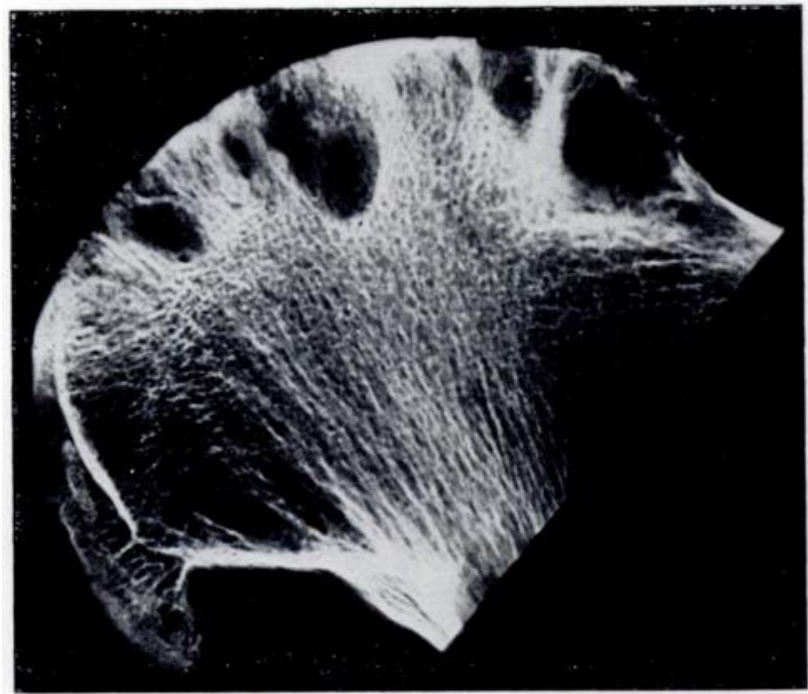

FIG. 13

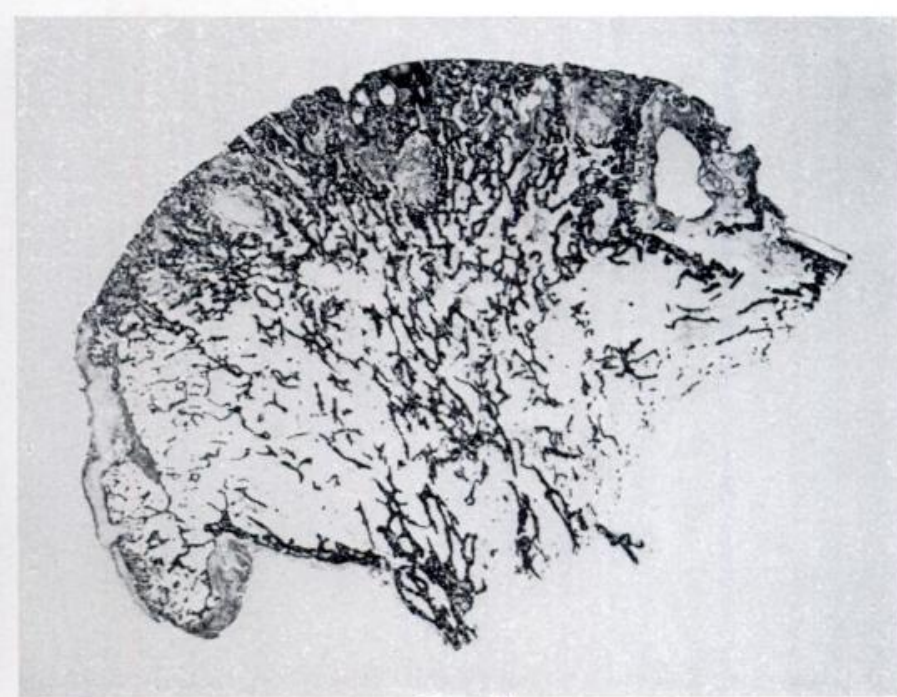

FIG. 14

Figure 13-Radiograph of a midcoronal bone slice from the femoral head in Figure 12. The epiarticular osteophyte forms a prominent growth extending medially and inferiorly. Maximal bone changes with cyst formation are seen superiorly and laterally. Layers of subperiosteal new bone have thickened the calcar. Figure 14-Histological section from the same femoral head showing the changes in bone structure and osteophyte formation.

ative changes with cyst formation were most marked in the antero-superior and lateral segment of the femoral head. As with all groups, thickening of the calcar was a constant feature. Lateral rotation deformity and lateral displacement of the femoral head within the acetabulum in a pendant-like manner from the medial and posteromedial aspect of the femoral head. Marked cyst formation and bone destruction involving the superior and lateral segment of the femoral head was accompanied by upward and lateral migration of the deformed femoral head 
within the acetabulum. Fixed deformities of flexion, lateral rotation and adduction were prominent clinically. Type III (Figs. 15 to 17)-In this type the femoral head
Type IV (Figs. 18 to 20)-Peripheral marginal osteophytes were also most marked in cases of acetabular protrusio. When bone destruction was followed by upward migra-

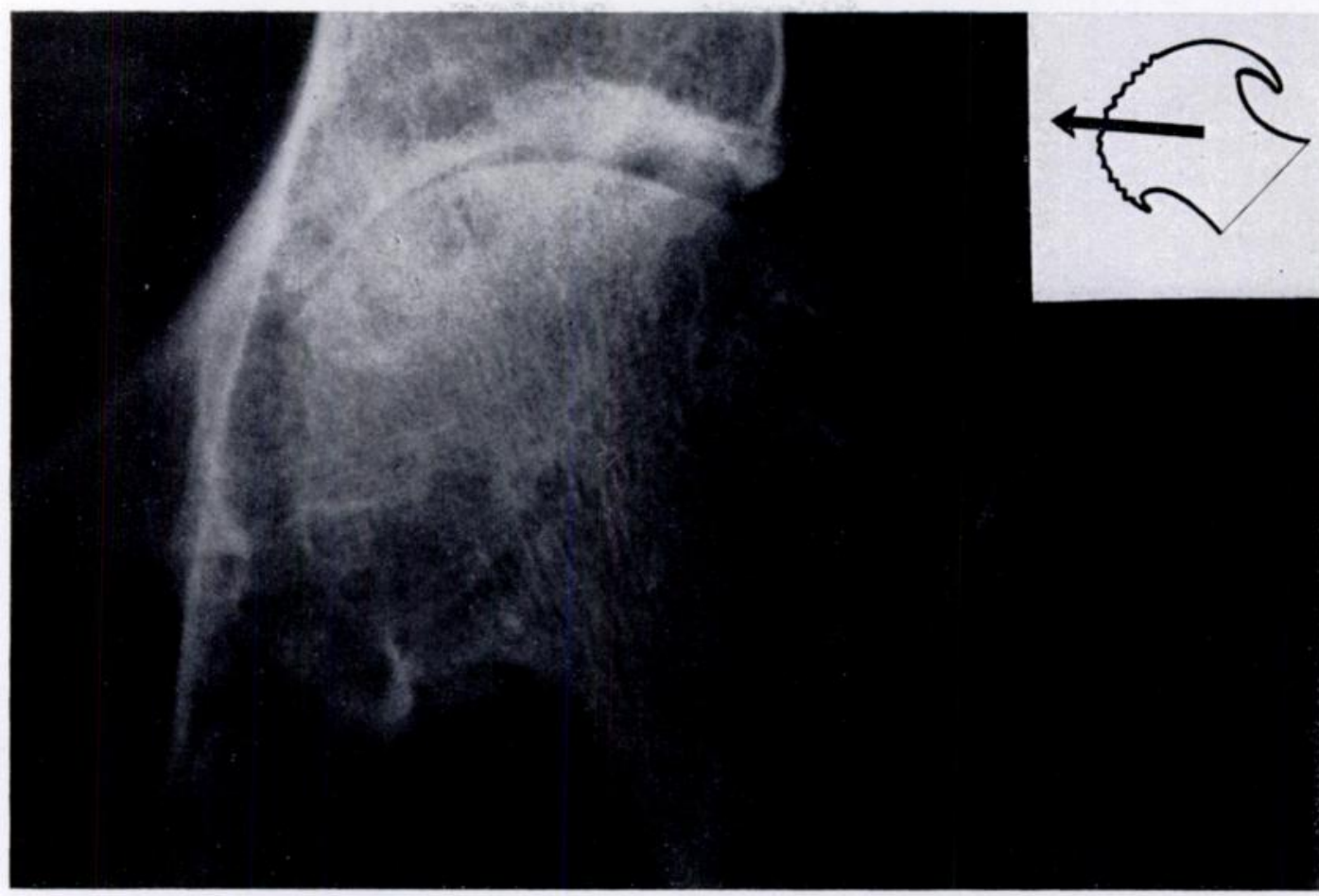

FIG. 15

Radiograph of an osteoarthritic hip showing Type III changes. Loss of medial joint space is promincnt and marginal osteophytes have formed at the periphery of the femoral head.

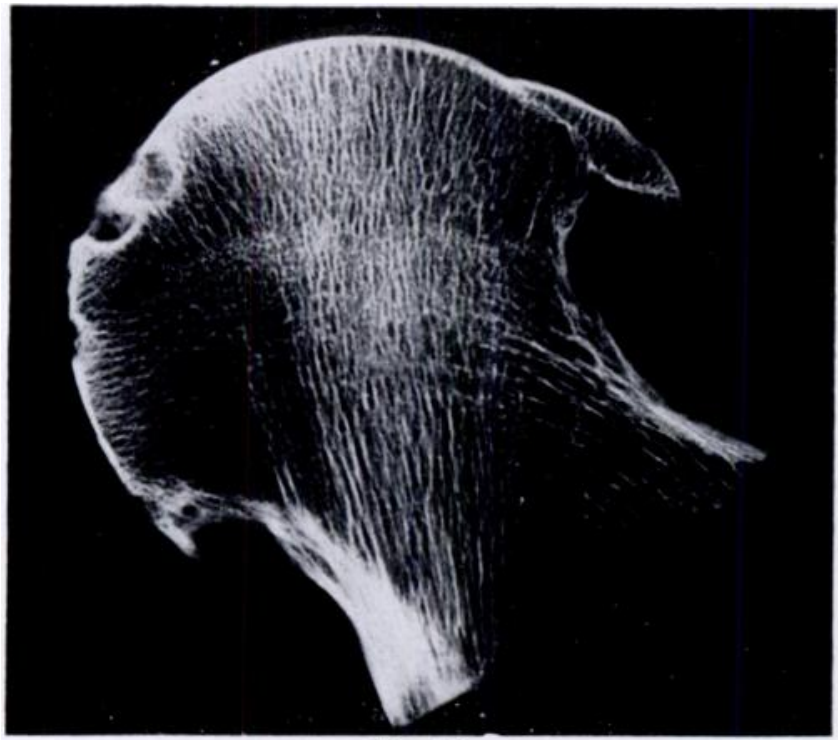

FIG, 16

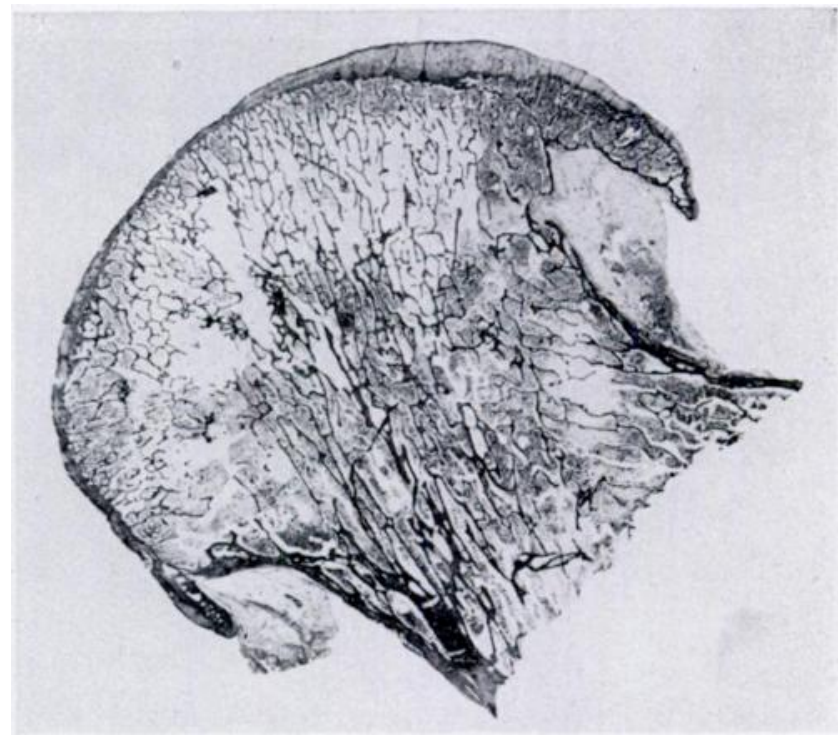

FIG. 17

Figure 16-Radiograph of a midcoronal bone slice from the femoral head in Figure 15. Thickening of the calcar is prominent. The same slice with uptake of tetracycline and ${ }^{32} \mathrm{P}$ bone label is shown in Figures 21 to 23 . Figure 17-Histological section from the same femoral head. Loss of cartilage is most marked medially.

was characteristically encircled by a ring of peripheral marginal osteophytes, with degenerative and destructive changes involving the medial and postero-medial surface. The bone changes were most marked in these areas and the associated bone cysts were usually small and circumferentially placed. tion of the femoral head within the acetabulum, the peripheral osteophyte ring was correspondingly more prominent along the inferior margin of the head.

Of the four categories, changes of the Type I and Type II pattern were most commonly seen in men and Types III and IV in women. 


\section{DISCUSSION}

The topography of osteophytes involving the femoral head was described by Harrison, Schajowicz and Trueta (1953), who noted the importance of growth in areas of osteophytes were found to be marginal growths arising principally from the periphery of the femoral head but also at the central foveal area. Epiarticular osteophytes were extensions of these marginal growths, the growth usually involving the medial and postero-medial surface

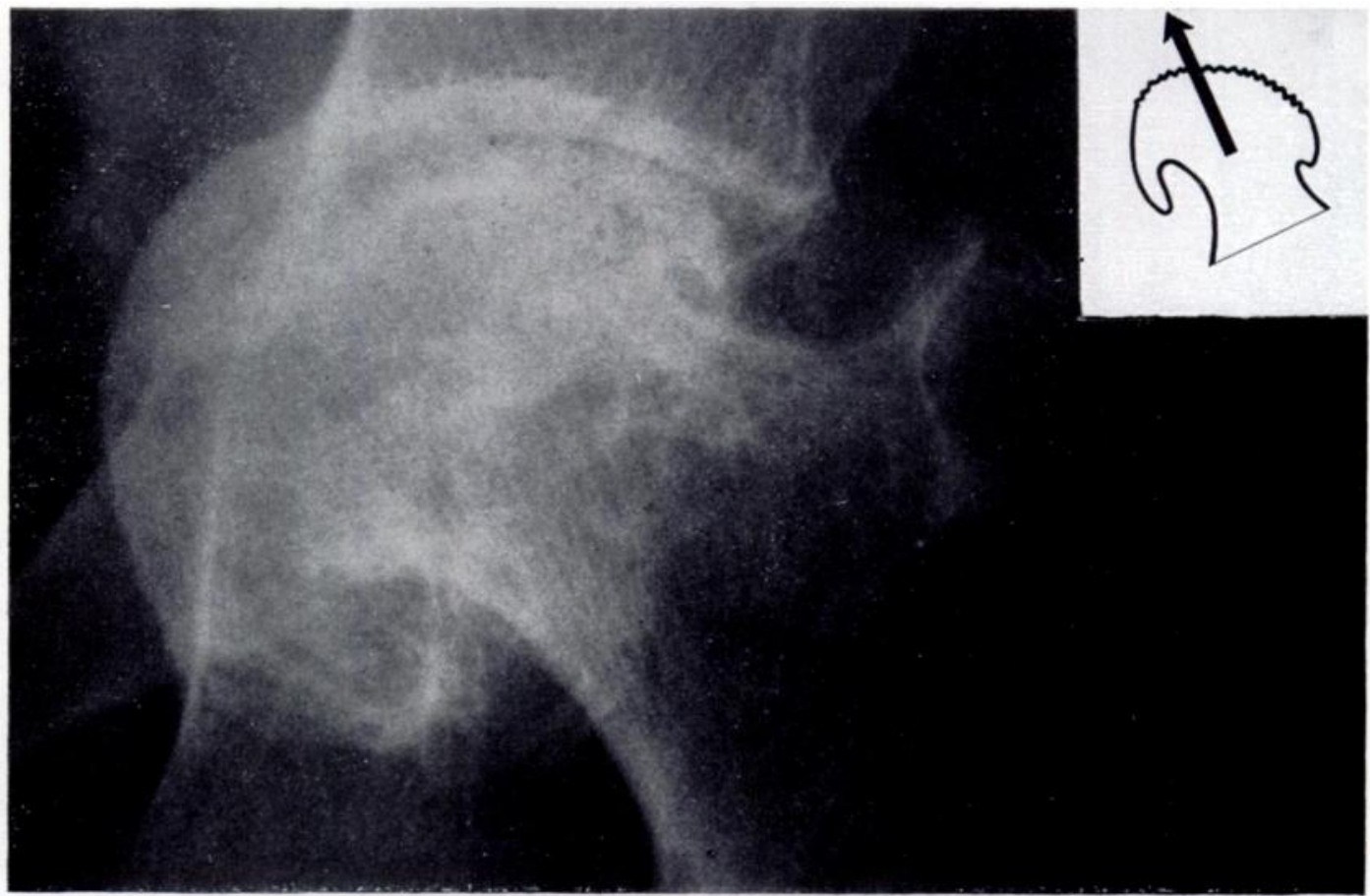

FIG. 18

Radiograph showing Type IV changes. Acetabular protrusion is present and peripheral marginal osteophytes are seen.

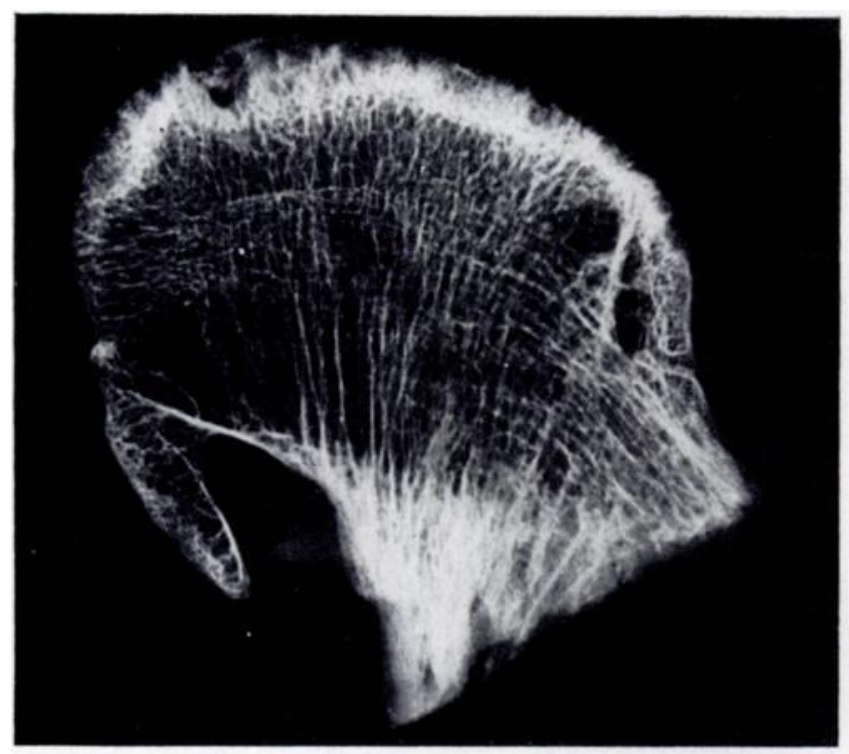

Fig. 19

Radiograph of a midcoronal bone slice from the femoral head in Figure 18 showing bone destruction superiorly and marginal osteophyte formation particularly inferiorly.

low joint stress. These authors could see no justification in referring to osteophytes as marginal structures and stated that growth occurred in any area of low joint stress, of which the peripheral border of the articular cartilage was but one. In the present study, however, most of the

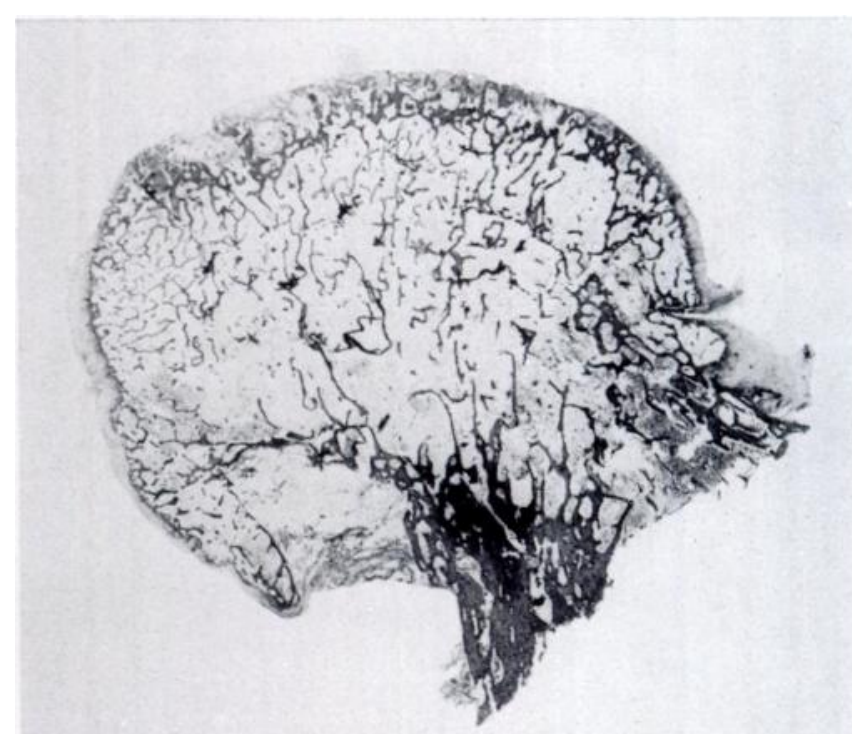

Fig. 20

Histological section from the same head. Small peripherally placed cysts lie adjacent to the area of maximal degeneration. Marked thickening of the calcar is present.

the of head. Subarticular osteophytes were the only osteophytes not arising from marginal zones. These were occasionally found as small plaques of bone in the deepest layers of the articular cartilage but did not commonly form macroscopic growths. 
The marginal osteophyte grows by a form of enchondral ossification with progressive changes of cellular proliferation, differentiation and elaboration of intercellular matrix. This is accompanied by advancing mineralisation,

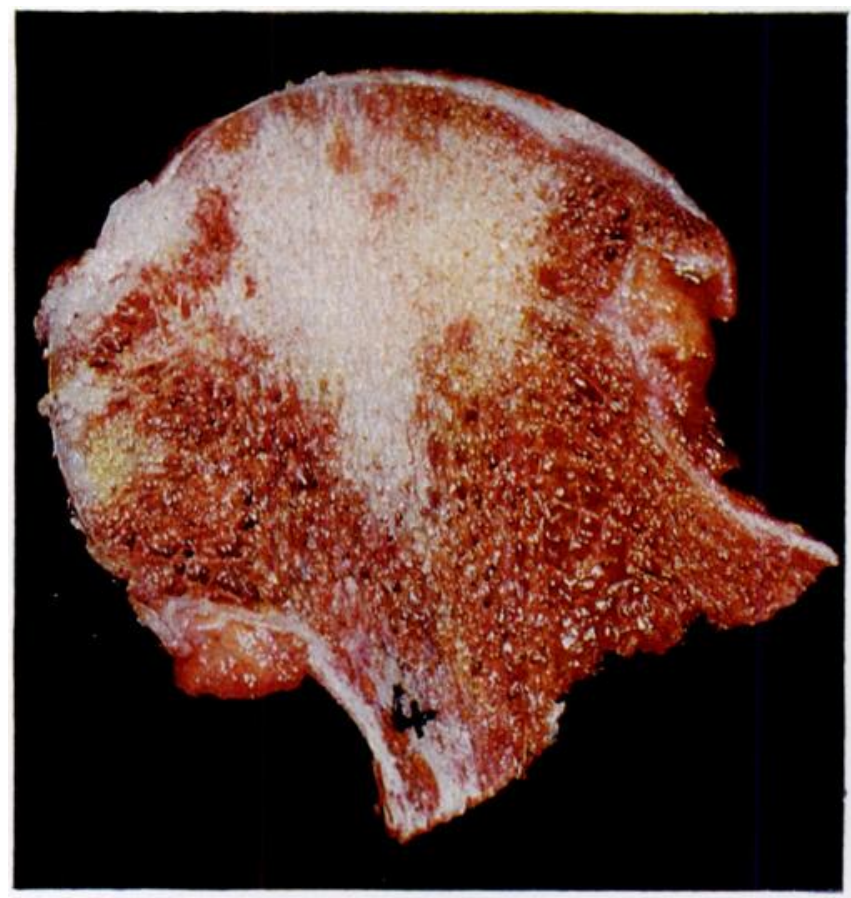

FiG. 21 in the osteophyte, and may in part be the result of lack of orientation of intercellular collagen.

The response of existing articular cartilage and its contribution to growth of the epiarticular osteophyte was

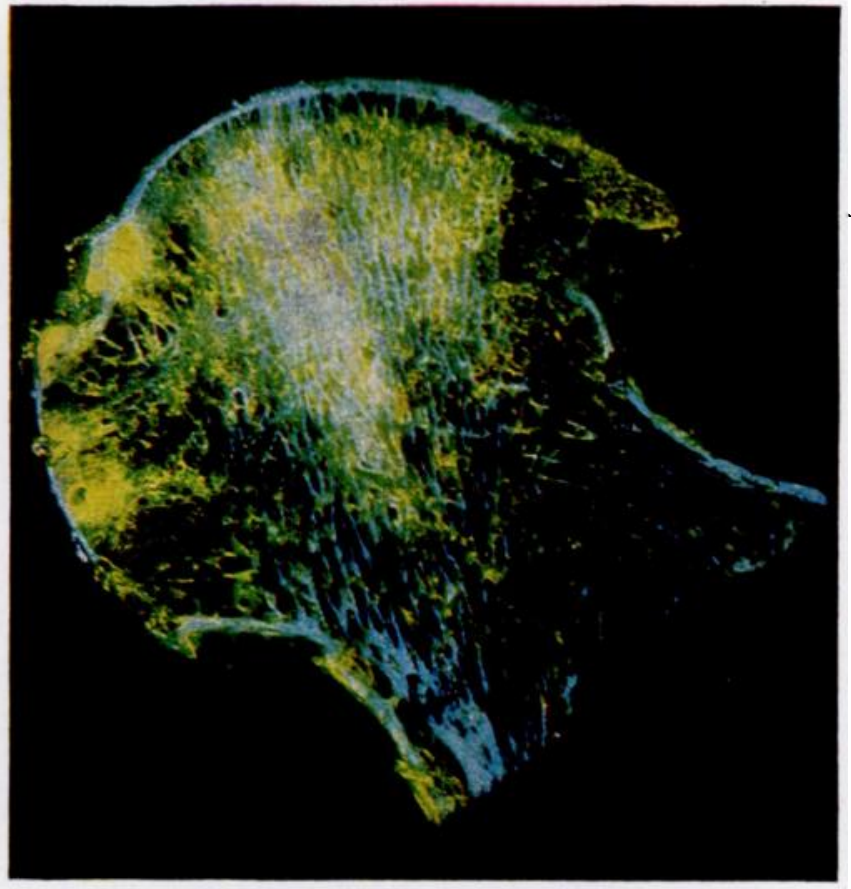

Fro. 22

Figure 21-A midcoronal bone slice labelled with tetracycline and radioactive ${ }^{32} \mathrm{P}$. Slab radiography and histology of the same slice are shown in Figures 16 and 17. Figure 22-The bone slice in Figure 21 viewed with ultra-violet light and showing tetracycline fluorescence in areas of new bone formation. Uptake is prominent medially in areas adjacent to maximal cartilage loss and bone degeneration. Fluorescence is also seen in the marginal osteophytes and in the region of the calcar where new subperiosteal bone is also being formed.

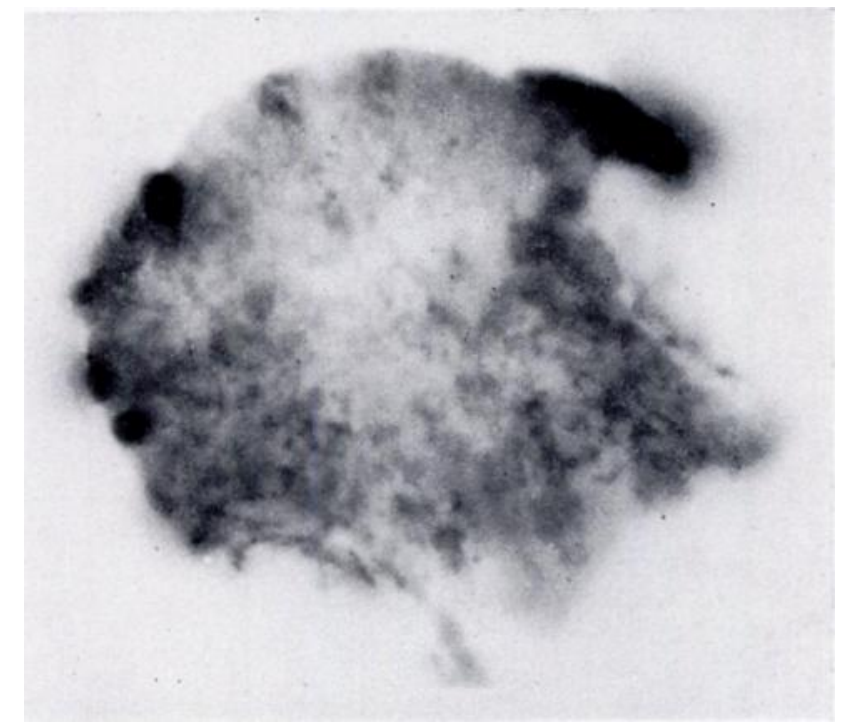

Fig. 23

Slab autoradiograph of the bone slice shown in Figures 21 and 22 showing maximal uptake of ${ }^{32} \mathrm{P}$ in areas of active osteogenesis.

vascular invasion and new bone formation. Thesechanges resemble to some extent those seen in the epiphysial plate of the immature growing long bone, but columnation of cells and orderly progression of differentiation is not seen of interest. Recent research indicates that regeneration of both cells and matrix can occur in injured and in osteoarthritic articular cartilage (Cruess 1971; Mankin and Lippiello 1970). At the apex of the advancing 
epiarticular osteophyte it was found that changes within the articular cartilage varied with the zone involved. Cartilage cells near the surface appeared active, with apparent proliferation and differentiation preceding enchondral new bone formation. The deeper layers of the cartilage showed only a limited cellular response, and vascular invasion was accompanied by gradual replacement of the existing cartilage matrix by bone. The present study suggests that cells in the superficial zone of articular cartilage retain the ability to undergo morphological change and participate actively in the process of enchondral bone growth. Cells in the deeper zone do not appear to retain this potential to the same degree. These findings are at variance with the hypothesis proposed by McKibbin and Holdsworth (1967) who, on the basis of an experimental study, suggested that the superficial layer of articular cartilage was destined from its origin to serve as articular cartilage and was incapable of ossification. It must be pointed out, however, that with growth of the epiarticular osteophyte, ossification is extending into degenerate articular cartilage and not into normal cartilage.

Although the mode of osteophyte growth has been described, factors initiating and maintaining this growth remain unknown. Collins (1949) described the circumference of articular cartilage as a region distinguished not only by its great vascularity, but also by the grouping together of partly differentiated mesenchymal tissues, fibrous connective tissue, perichondrium, periosteum, synovial membrane, bone and cartilage. In the femoral head the same grouping of tissues is seen in the central foveal region. At these junctional areas cellular proliferation and differentiation, followed by new bone formation, may be initiated by the presence of accumulated cartilage and bone detritus arising from the more centrally placed areas of joint destruction. Lloyd-Roberts (1953) described the considerable amount of debris found in the synovium of osteoarthritic hips, and accumulation was noted in the recesses of capsular reflection, particularly inferiorly and below the femoral neck. In the present study these findings were confirmed: hypertrophied synovium containing detritus was most prominent at the articular margins and in areas of synovial reflection.

Once growth of the marginal osteophyte is initiated, the size and shape of growth appear to be influenced by the displacement of the femoral head within the acetabulum. The direction, degree and rate of displacement of the head all appear important factors in determining the ultimate pattern of principal osteophyte formation. In cases examined in which bone destruction and migration of the head occurred rapidly, osteophytes were correspondingly less prominent. When bone destruction and displacement of the head were considerable, but had been slowly progressive over a longer period, the osteophytes were commonly large. It seems that as the femoral head migrates, pressure and stress relationships between the head, the capsule and the acetabulum alter, the osteophyte growing in the direction of least contact or resistance. There was no evidence that osteophyte growth in itself caused displacement of the femoral head, but sizeable outgrowths could be a factor in the subsequent limitation of joint movement.

In a previous study using ${ }^{32} \mathrm{P}$ and tetracycline bonemarkers it was shown that considerable osteogenic activity was present within the osteoarthritic femoral head, and was most marked in advanced stages of the disease. Both enchondral and appositional new bone formation was noted, particularly surrounding cysts and in some areas of bone sclerosis (Jeffery 1973). Similar forms of new bone formation also taking up these bone labels extend outside the femoral head and neck (Figs. 21 to 23). These areas of active osteogenesis altering both the internal and external bony structure of the osteoarthritic hip would account for the increased uptake of bone-seeking isotopes described by previous authors using external bone scanning techniques (Danielsson, Dymling and Heripret 1963; Koláŕ, Vyhnănek, Bek, Drápelová, Janko and Babický 1967).

I wish to thank Mr B. Glynn-Jones who prepared the histological sections and also the staff of the Photographic Department of the Otago Medical School who prepared the illustrations.

\section{REFERENCES}

Ball, J. (1957) A simple method of defining osteoid in undecalcified sections. Journal of Clinical Pathology, 10, $281-282$.

Collins, D. H. (1949) The Pathology of Articular and Spinal Diseases. London: Edward Arnold \& Co.

Cruess, R. L. (1971) Cartilage repair. Journal of Bone and Joint Surgery, 53-B, 365.

Danielsson, L. G., Dymling, J-F., and Heripret, G. (1963) Coxarthrosis in man studied with external counting of $\mathrm{Sr}^{85}$ and Ca ${ }^{67}$. Clinica Orthopaedics and Related Research, 31, 184-198.

Harrison, M. H. M., Schajowicz, F., and Trueta, J. (1953) Osteoarthritis of the hip: a study of the nature and evolution of the disease. Journal of Bone and Joint Surgery, 35-B, 598-626.

Jefiery, A. K. (1973) Osteogenesis in the osteoarthritic femoral head. Journal of Bone and Joint Surgery, 55-B, 262-272.

Kolår, J., Vyhnảnek, L., Drápelová, D., Bek, V., Janko, L., and Babický, A. (1967) Degenerativní chorobykloubní při osteologické diagnostice se 85-Sr. Fysiatrický a Reumatologicky véstnik, 45, 65-72.

Lloyd-Roberts, G. C. (1953) The role of capsular changes in osteoarthritis of the hip joint. Journal of Bone and Joint Surgery, 35-B, 627-642.

McKibbin, B., and Holdsworth, F. W. (1967) The dual nature of epiphysial cartilage. Journal of Bone and Joint Surgery, 49-B, 351-361.

Mankin, H. J., and Lippiello, L. (1970) Biochemical and metabolic abnormalities in articular cartilage from osteo-arthritic human hips. Journal of Bone and Joint Surgery, 52-A, 424-434.

Wiberg, G. (1939) Studies on dysplastic acetabula and congenital subluxation of the hip joint. Acta chirurgica Scandinavica, 83, Supplement 58. 